\title{
Effects of Acute Hyperglycemia on Myocardial Glycolytic Activity in Humans
}

Judith A. Wisneski, William C. Stanley, Richard A. Neese, and Edward W. Gertz

Departments of Medicine and Radiology, and the Cardiovascular Research Institute, University of California at San Francisco, and the Veterans Administration Medical Center, San Francisco, California 94121

\begin{abstract}
The effects of hyperglycemia on myocardial glucose metabolism were investigated in seven healthy male subjects (age $24 \pm 4 \mathrm{yr}) \cdot\left[6-{ }^{14} \mathrm{C}\right] \mathrm{Glucose}$ and $\left[\mathrm{U}-{ }^{13} \mathrm{C}\right]$ lactate were infused as tracers. Circulating glucose was elevated to two hyperglycemic levels using a clamp technique for $1 \mathrm{~h}$ at each level. The mean arterial glucose concentration was $4.95 \pm 0.29$ (control), $8.33 \pm 0.31$ and $10.84 \pm 0.60 \mu \mathrm{mol} / \mathrm{ml}$, respectively. Glucose extraction increased significantly from control $(0.15 \pm 0.13 \mu \mathrm{mol} /$ $\mathrm{ml})$ during each level of the glucose clamp $(0.28 \pm 0.12, P$ $<0.02$, and $0.54 \pm 0.14 \mu \mathrm{mol} / \mathrm{ml}, P<0.005$, respectively). Myocardial production of ${ }^{14} \mathrm{CO}_{2}$ showed that during control $9 \pm 10 \%$ of exogenous glucose was oxidized immediately upon extraction. Despite a significant increase in the amount of exogenous glucose oxidized with level II hyperglycemia, it represented only $32 \pm 10 \%$ of the glucose extracted. $\left[{ }^{13} \mathrm{C}\right]$ Lactate analysis showed that the myocardium was releasing lactate; during control $\mathbf{4 0} \pm 30 \%$ of this lactate was derived from exogenous glucose and during hyperglycemia this value increased to $97 \pm 37 \%(P<0.005)$. Thus, these data show that during short-term hyperglycemia, myocardial glucose extraction is enhanced. However, despite increases in exogenous glucose oxidation and the contribution of exogenous glucose to lactate release, the majority of the extracted glucose (i.e., 57\%) is probably stored as glycogen. (J. Clin. Invest. 1990. 85:16481656.) myocardial metabolism • glucose oxidation • lactate release $\bullet$ glycogen $\bullet$ free fatty acids
\end{abstract}

\section{Introduction}

Hyperglycemic or euglycemic insulin clamp techniques have been used to investigate total body glucose uptake and oxidation, and glucose metabolism in skeletal muscle and other organ systems in healthy human subjects (1-6). However, little is known about the effects of hyperglycemia on glucose utilization in the hearts of intact animals and humans. Previous studies have measured the arterial (A) ${ }^{1}$ and coronary sinus (CS) difference for glucose and have calculated an oxygen extraction ratio (OER); the OER is based on the assumption that the entire A - CS difference is oxidized. These calculations suggest that glucose contributes from 15 to $55 \%$ of oxidative

Address reprint requests to $\mathrm{Dr}$. Wisneski, $111 \mathrm{Cl}$ Veterans Administration Medical Center, 4150 Clement Street, San Francisco, CA 94121. Received for publication 16 June 1989 and in revised form 5 December 1989.

1. Abbreviations used in this paper: A, arterial; CS, coronary sinus; OER, oxygen extraction ratio.

The Journal of Clinical Investigation, Inc.

Volume 85, May 1990, 1648-1656 metabolism under fasting conditions (7-15). During acute hyperglycemia, the myocardial extraction of glucose significantly increases; OER data obtained during hyperglycemia imply that glucose becomes the major substrate for oxidative metabolism under this condition $(7-9,12-13,15)$.

Numerous studies have examined the effects of elevated glucose during myocardial hypoxia or ischemia. The concept that glucose enhances myocardial function during pathologic conditions dates back to Goulston in 1911 (16). In 1914 Budingen reported that eight patients with severe angina or myocardial infarction improved after glucose infusion (17). Insulin was later given with glucose to promote glucose transport and potassium was added to maintain the circulating level and replace intracellular losses due to ischemia. In the 1960 s SodiPallares further popularized this treatment initially for arrhythmias, and later for angina $(18,19)$. Glucose-insulin-potassium infusions have been advocated for patients with acute myocardial infarctions by other investigators and have also been administered before cardiac surgery (20-27). Animal studies have shown that glucose infusions increase ATP levels and glycogen stores, and reduce tissue necrosis during acute infarctions (28-30). Although several studies have demonstrated that elevating the circulating glucose concentration increases the $\mathrm{A}-\mathrm{CS}$ glucose difference in humans with coronary disease $(8,31)$, no study has assessed the activity of the various glycolytic pathways during hyperglycemia in healthy or ischemic human subjects. The effects of hyperglycemia on glucose oxidation, activity of the nonoxidative (anaerobic) pathway, and glycogen storage in the human myocardium is not known.

The purpose of this study was to evaluate the effects of acute short-term hyperglycemia on myocardial glucose metabolism in healthy young human subjects. Dual carbon-labeled isotopes $\left(\left[6-{ }^{14} \mathrm{C}\right]\right.$ glucose and $\left[\mathrm{U}-{ }^{13} \mathrm{C}\right]$ lactate) were used to quantitate myocardial glucose oxidation, lactate release and the contribution of exogenous glucose to lactate release. A hyperglycemic clamp technique was used to elevate and stabilize circulating glucose levels.

\section{Methods}

Subject selection. Young healthy male volunteers were sought. The volunteers underwent a complete medical history, physical examination, and laboratory tests. The tests included an electrocardiogram, complete blood count, liver function tests, blood urea nitrogen and creatinine determinations, urinalysis, and a fasting glucose. In addition, the subject had to complete at least stage $\mathrm{V}$ of the standard Bruce protocol (32) and achieve $95 \%$ of his maximal predicted heart rate on a treadmill exercise test. Subjects with a family history of diabetes or a history of chronic drug use or smoking were excluded. If there was no evidence of cardiac or any other major systemic illness and all the laboratory tests were within normal limits, the volunteer was accepted as a subject. The examination and exercise test were performed at least $1 \mathrm{wk}$ before the metabolic study.

The protocol was approved by the Committees on Human Research of the University of California and the Veterans Administration 
Medical Center at San Francisco, CA. The use of radioisotopes was approved by the Radiation Safety Committee of the Veterans Administration Medical Center. Each subject was informed of the nature, purpose, and possible risks involved in the study before written consent was obtained.

Protocol. The subjects were instructed to maintain a regular diet; no dietary manipulations were performed. The subjects reported for the procedure at 8 a.m. after a $10-15-\mathrm{h}$ fast. No premedication was given. A short Teflon catheter was inserted percutaneously into a left antecubital vein for isotope infusion. A local anesthetic ( $2 \%$ lidocaine) was used to perform a venous cutdown in the right arm; and a 7F thermodilution flow coronary sinus catheter (Webster Laboratories, Baldwin Park, CA) was inserted as previously published (33). In addition, a long Teflon catheter was also inserted into this vein and placed in the mid-brachial region for the glucose infusion during the clamp protocol. A short polyethylene catheter was placed into the right brachial artery.

To quantitate myocardial substrate utilization, D- $\left[6-{ }^{14} \mathrm{C}\right] \mathrm{glucose}$ and $\mathrm{L}-\left[\mathrm{U}-{ }^{13} \mathrm{C}\right]$ lactate were infused using a primed continuous infusion technique. D- $\left[6-{ }^{14} \mathrm{C}\right]$ Glucose was obtained from New England Nuclear, Boston, MA (sp act $56.1 \mathrm{mCi} / \mathrm{mmol}$ ). It was sterilized by microfiltration $(0.22 \mu \mathrm{m}$ bacteriologic filter [Millipore Corp., Bedford, MA]) and diluted in $0.9 \% \mathrm{NaCl}$. $\mathrm{L}-\left[\mathrm{U}-{ }^{13} \mathrm{C}\right]$ Lactate $(>99 \%$ enrichment) was obtained from Merck \& Co., Rahway, NJ, as L-[U- $\left.{ }^{13} \mathrm{C}\right]$ sodium lactate and sterilized as above. Priming doses of $16 \mu \mathrm{Ci}$ of $\left[6-{ }^{14} \mathrm{C}\right]$ glucose and $55 \mathrm{mg}$ of $\left[\mathrm{U}-{ }^{13} \mathrm{C}\right]$ lactate were given intravenously; this was followed by a continuous infusion of $\left[6-{ }^{14} \mathrm{C}\right]$ glucose at $10 \mu \mathrm{Ci} / \mathrm{h}$ and $\left[\mathrm{U}-{ }^{13} \mathrm{C}\right]$ lactate at $65 \mathrm{mg} / \mathrm{h}$.

At least $20 \mathrm{~min}$ is required to achieve equilibration of the arterial and coronary sinus specific activity and the myocardial $\mathrm{CO}_{2}$ pool when lactate is labeled with a tracer, and $25-30 \mathrm{~min}$ is required for a glucose tracer $(33,34)$. Thus to ensure equilibration, the first control blood samples were obtained at $42.0 \pm 6.6 \mathrm{~min}$ after the priming bolus and the start of the continuous isotope infusion in this study.

Arterial and coronary sinus blood samples were drawn simultaneously. Samples were obtained for chemical concentrations of glucose, lactate, alanine, and FFA, specific activities $\left({ }^{14} \mathrm{C}\right)$ of glucose and lactate, ${ }^{13} \mathrm{C}$-enrichment of lactate, ${ }^{14} \mathrm{CO}_{2}$, and the $\mathrm{O}_{2}$ content. In addition, arterial samples were drawn for insulin concentrations. Immediately after every metabolic blood sample, the heart rate, arterial pressure, and coronary sinus blood flow were recorded. Coronary sinus blood flow was determined by a thermodilution technique using room temperature normal saline infused at a rate of $46 \mathrm{ml} / \mathrm{min}$ (35).

Two sets of samples were obtained during control (i.e., at fasting glucose concentrations) $10 \mathrm{~min}$ apart. The fasting arterial glucose was determined immediately using a glucose analyzer (Yellow Springs Instruments, Yellow Springs, $\mathrm{OH}$ ). In the subjects undergoing the hyperglycemic clamp protocol, the circulating glucose was elevated after the control samples by $60 \mathrm{mg} / 100 \mathrm{ml}$ above the fasting concentration using the hyperglycemic clamp technique of DeFronzo et al. (1). The arterial glucose was then stabilized at this value (level $\mathrm{I}$ ) for $\mathrm{l} \mathrm{h}$ and then further elevated and stabilized at $\sim 100 \mathrm{mg} / 100 \mathrm{ml}$ above the fasting value for an additional hour (level II). Arterial and coronary sinus samples were obtained at 30,45 , and 60 min during each level of the glucose clamp. The arterial glucose concentration was monitored every 5-10 min using the glucose analyzer. The glucose infusion rate was kept constant after $20 \mathrm{~min}$ at each level of the glucose clamp to minimize fluctuations in arterial glucose specific activity. The mean glucose infusion rate was $3.56 \pm 0.48 \mathrm{mg} \cdot \mathrm{kg}^{-1} \cdot \mathrm{min}^{-1}$ for level I and $6.21 \pm 1.31 \mathrm{mg} \cdot \mathrm{kg}^{-1} \cdot \mathrm{min}^{-1}$ for level II.

In the subjects serving as controls, $\mathrm{D}-\left[6-{ }^{14} \mathrm{C}\right]$ glucose and $\mathrm{L}-\left[\mathrm{U}-{ }^{13} \mathrm{C}\right]-$ lactate were infused as described for a duration of $3 \mathrm{~h}$. Simultaneous arterial and coronary sinus blood samples were obtained $45 \mathrm{~min}$ after the initiation of the isotope infusion and every $30 \mathrm{~min}$ thereafter during the 3-h infusion period. The samples were analyzed as previously described.

Chemical analysis. Weighed blood samples for analysis of lactate, glucose, alanine, specific activities, and ${ }^{13} \mathrm{C}$-lactate enrichments were mixed immediately with a measured volume of cold $7 \%$ perchloric acid $(1: 2 \mathrm{vol} / \mathrm{vol})$ and centrifuged. The protein-free supernatant was removed and stored at $-4^{\circ} \mathrm{C}$ for future analysis. The coefficient of variation and the methodology for the chemical substrate analyses and the determination of specific activities have been published previously for our laboratory $(33,34)$.

$\left[\mathrm{U}-{ }^{13} \mathrm{C}\right]$ Lactate content was assessed by gas chromatography/mass spectrometry using the method of Tserng et al. (36). Lactate was isolated from deproteinized blood using two ion-exchange columns $\left(\mathrm{H}^{+}\right.$ and formate) and then converted to the $n$-propylamide heptafluorobutyrate derivative. A standard curve was prepared using labeled and unlabeled lactic acid (0.0-2.0\%) and derivatized. The lactate recovered from blood was compared to the standard curve at $\mathrm{m} / \mathrm{z} 327$ vs. 330 using a gas chromatograph (model 2400; Infratronics, Dohrmann Envirotech, Mountain View, CA) interfaced to a mass spectrometer (MS-12; Kratos Analytical Instruments, Ramsey, NJ), modified for selected ion recording analysis (37). The gas chromatograph used a $10^{\prime}$ DB-17, $1.0 \mu \mathrm{m}$ film thickness, Megabore column (J\&W Scientific, Folsom, CA) at $90^{\circ} \mathrm{C}$ isothermal with a helium flow rate of $4 \mathrm{ml} / \mathrm{min}$.

The ${ }^{14} \mathrm{CO}_{2}$ was collected directly from blood by a diffusion method, a modification of the procedure by Hagenfeldt (38). Blood samples (5 $\mathrm{ml}$ ) were placed in the outer well of a double-chambered Erlenmeyer flask. A standard 50-ml Erlenmeyer flask was modified to contain a center well by a glass blower. With the system airtight, lactic acid was added to the blood and the flask was rotated on a shaker table (American Rotator; American Scientific Products, McGaw Park, IL) for a minimum of $2 \mathrm{~h}$ (range 2-4 h) at a rotational speed of $100 \mathrm{rpm}$ at room temperature. The center well of the flask contained $1.0 \mathrm{M} \mathrm{NaOH}$, which traps the released ${ }^{14} \mathrm{CO}_{2}$ as $\mathrm{NaH}^{14} \mathrm{CO}_{3}$. A portion of the $\mathrm{NaH}^{14} \mathrm{CO}_{3}$ solution was mixed with Aquasol (New England Nuclear, Boston, MA) and counted. The recovery of ${ }^{14} \mathrm{CO}_{2}$ from $\mathrm{NaH}^{14} \mathrm{CO}_{3}$ added to whole blood was $96.6 \%$; the coefficient of variation for this method was $0.8 \%$ (eight analyses of one sample containing $\sim 85-90$ $\mathrm{dpm} / \mathrm{ml}$ )

Samples for plasma FFA and insulin concentrations were immediately placed in iced, heparinized glass tubes, centrifuged at $4^{\circ} \mathrm{C}$, and separated. The FFA were determined using gas chromatography by a modification of the method of Ko and Royer (39). Insulin was measured using a radioimmunoassay (Diagnostic Products, Inc., Los Angeles, CA) (40). Alanine concentrations were obtained on the proteinfree supernatant by an enzymatic method (41). The $\mathrm{O}_{2}$ contents were measured by the manometric technique of Van Slyke and Neill (42). All isotopic and chemical analyses were performed in duplicate.

Calculations. The chemical extraction $(\mu \mathrm{mol} / \mathrm{ml})$ for a given substrate was calculated from the arterial and coronary sinus substrate chemical concentration as [A] - [CS], where [A] is the arterial concentration and $[\mathrm{CS}]$ is the coronary sinus concentration. The myocardial uptake $(\mu \mathrm{mol} / \mathrm{min})$ was calculated from the chemical or isotopic extraction $(\mu \mathrm{mol} / \mathrm{ml}) \times$ coronary sinus flow.

The isotopic lactate extraction ratio (percent) for $\left[\mathrm{U}-{ }^{13} \mathrm{C}\right]$ lactate was calculated from the concentration of $\left[\mathrm{U}^{-13} \mathrm{C}\right]$ lactate in the artery and coronary (cor) sinus as $[\mathrm{A}] \times \%^{13} \mathrm{C}_{3}$ in artery $-[\mathrm{CS}] \times \%{ }^{13} \mathrm{C}_{3}$ in coronary sinus $/[\mathrm{A}] \times \%^{13} \mathrm{C}_{3}$ in artery $\times 100$, where $\%{ }^{13} \mathrm{C}_{3}=\left[{ }^{13} \mathrm{C}_{3}\right]$ lactate/chemical lactate $\times 100\left(\%{ }^{13} \mathrm{C}_{3}\right.$ is obtained directly from gas chromatography/mass spectrometry).

The myocardial isotopic lactate extraction $(\mu \mathrm{mol} / \mathrm{ml})$ was determined from the $\left[\mathrm{U}-{ }^{13} \mathrm{C}\right]$ lactate extraction ratio as $[\mathrm{A}] \times$ isotopic lactate extraction ratio $(\%) / 100$.

Myocardial lactate release $(\mu \mathrm{mol} / \mathrm{ml})$ is the difference between the isotopic lactate and the chemical lactate extraction and was calculated as isotopic lactate extraction - ([A] - [CS]).

When $\left[6-{ }^{14} \mathrm{C}\right]$ glucose is used as a tracer, glucose oxidation $(\mu \mathrm{mol} /$ $\mathrm{ml}$ ) can be calculated from the myocardial production of ${ }^{14} \mathrm{CO}_{2}$ and the arterial specific activity as $(\mathrm{CS}-\mathrm{A})^{14} \mathrm{CO}_{2} \mathrm{dpm} / \mathrm{ml} /$ arterial specific activity of glucose.

Since other substrates are labeled secondarily when tracers are infused, the $(\mathrm{CS}-\mathrm{A}){ }^{14} \mathrm{CO}_{2}$ was corrected for oxidation of the secondarily labeled substrates as previously published $(33,34)$. 
Using dual-carbon labeled isotopes of glucose and lactate and measuring the specific activities of glucose and lactate and the ${ }^{13} \mathrm{C}$ enrichment of lactate in the artery and coronary sinus allows quantitation of the conversion of exogenous glucose to lactate by the myocardium as previously reported (33).

The calculations for substrate contribution to myocardial oxidative metabolism were based on substrate extraction or glucose oxidation in $\mu \mathrm{mol} / \mathrm{ml}$, and the arterial-coronary sinus difference in oxygen content for the same sampling period expressed in $\mu \mathrm{mol} / \mathrm{ml}$. The oxygen equivalent ( $\mu \mathrm{mol}$ oxygen/ $\mu \mathrm{mol}$ ) is 6 for glucose, 3 for lactate, and 24.5 for FFA. The oxygen equivalent for the substrate was expressed as a percentage of the total oxygen difference in $\mu \mathrm{mol} / \mathrm{ml}$.

Myocardial oxygen consumption $(\mathrm{ml} / \mathrm{min}$ ) was calculated from the arterial and coronary sinus difference in the oxygen content $(\mathrm{ml} / 100$ $\mathrm{ml})$ and the coronary sinus flow as $(\mathrm{A}-\mathrm{CS}) \mathrm{O}_{2} \times \mathrm{CS}$ flow.

Statistical analysis. To compare myocardial substrate extraction, oxidation and utilization, and hemodynamic parameters during the two levels of the glucose clamp with control, the two-tailed paired $t$ test was used. Simple linear and multiple linear regression analyses were performed for the various metabolic parameters and the standard errors of the estimate were calculated (43). The data are presented as mean $\pm 1 \mathrm{SD}$ in the text and mean $\pm 1 \mathrm{SE}$ in the figures.

\section{Results}

The mean age of the seven healthy male subjects in the hyperglycemic clamp protocol was $24 \pm 4$ yr. The circulating substrate concentrations during control and both levels of the hyperglycemic clamp are shown in Fig. 1. During the hyperglycemic clamp an increase in arterial lactate was observed; while the arterial FFA fell significantly.

Hemodynamics. The mean heart rate and mean arterial pressure were $65 \pm 7 \mathrm{bpm}$ and $90 \pm 8 \mathrm{mmHg}$ during control (fasting), $66 \pm 7 \mathrm{bpm}$ and $92 \pm 8 \mathrm{mmHg}$ during level I of the glucose clamp and $70 \pm 8 \mathrm{bpm}$ and $92 \pm 7 \mathrm{mmHg}$ during level II of the clamp. The coronary sinus flow determined by a thermodilution technique was $101 \pm 26 \mathrm{ml} / \mathrm{min}$ for control, $97 \pm 20$ $\mathrm{ml} / \mathrm{min}$ for level I and $104 \pm 26 \mathrm{ml} / \mathrm{min}$ for level II. The calculated myocardial oxygen consumptions for these periods were
$12.5 \pm 2.7 \mathrm{ml} / \mathrm{min}, 11.1 \pm 2.4 \mathrm{ml} / \mathrm{min}$, and $11.7 \pm 2.9 \mathrm{ml} / \mathrm{min}$, respectively. There were no significant differences between control and level I or II of the glucose clamp for any of these parameters.

Myocardial substrate extraction. The myocardial extractions of glucose, lactate and FFA are presented in Fig. 2. The glucose and FFA extractions were calculated from the A - CS difference. Since $\left[\mathrm{U}-{ }^{13} \mathrm{C}\right]$ lactate was infused as a tracer, an isotopic extraction ratio was obtained for lactate. Significant increases in glucose and $\left[{ }^{13} \mathrm{C}\right]$ lactate extraction were demonstrated during the hyperglycemic clamp. Glucose extraction rose from a control value of $0.15 \pm 0.13$ to $0.54 \pm 0.14 \mu \mathrm{mol} / \mathrm{ml}$ during level II of the glucose clamp $(P<0.005)$. The isotopic lactate extraction increased from $0.24 \pm 0.12$ to $0.45 \pm 0.13$ $\mu \mathrm{mol} / \mathrm{ml}$, respectively, $(P<0.01)$. Myocardial FFA extraction fell significantly during both levels I and II of the glucose clamp, $0.18 \pm 0.05 \mu \mathrm{mol} / \mathrm{ml}$ for control and $0.08 \pm 0.04$ and $0.04 \pm 0.04 \mu \mathrm{mol} / \mathrm{ml}$ for levels I and II, respectively, $(P<0.01)$.

Using the blood flow obtained by the coronary sinus thermodilution technique, one can calculate the myocardial uptake expressed as micromoles per minute for these major substrates. During hyperglycemia, the changes observed in the myocardial extractions (micromoles per milliliter) were also seen in the calculated uptakes. The myocardial glucose uptake was $14.3 \pm 13.1 \mu \mathrm{mol} / \mathrm{min}$ during control, $29.2 \pm 16.4 \mu \mathrm{mol} /$ $\min (P<0.05)$ during level $\mathrm{I}$ and $53.8 \pm 20.9 \mu \mathrm{mol} / \mathrm{min}(P$ $<0.01)$ during level II of the hyperglycemic clamp. These values were $22.7 \pm 12.9,30.2 \pm 15.0(P<0.05)$, and $43.0 \pm 11.3$ $\mu \mathrm{mol} / \mathrm{min}(P<0.001)$, respectively, for the $\left[{ }^{13} \mathrm{C}\right]$ lactate uptake

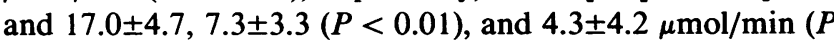
$<0.01$ ), respectively, for FFA uptake.

Circulating insulin values. In this study we made no attempt to suppress endogenous insulin excretion during the glucose clamp. The mean fasting arterial plasma insulin concentration was $5 \pm 3 \mu \mathrm{U} / \mathrm{ml}$, during level I and level II of the clamp these values rose to $19 \pm 10 \mu \mathrm{U} / \mathrm{ml}(P<0.05)$ and $30 \pm 8$ $\mu \mathrm{U} / \mathrm{ml}(P<0.01)$, respectively.

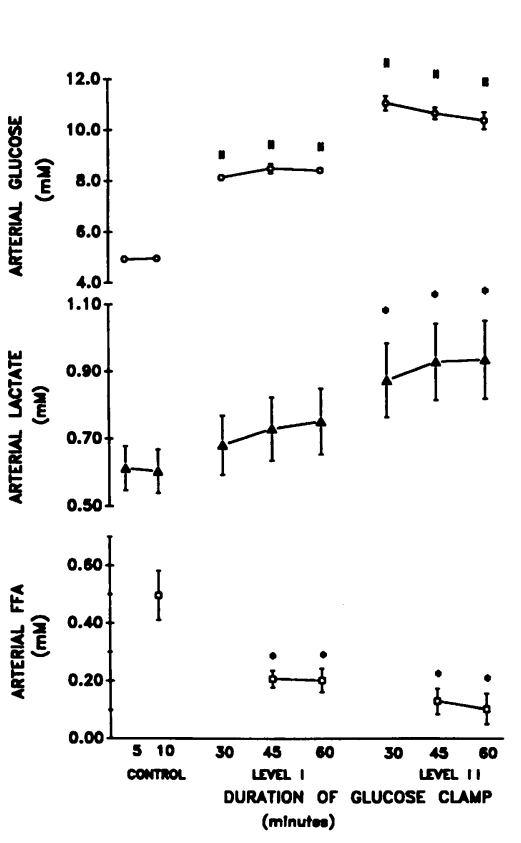

Figure 1. Circulating glucose (top), lactate (middle) and free fatty acids (FFA) (bottom) concentrations are shown during fasting (control) and level I and level II of the glucose clamp. The circulating glucose concentration was elevated and stabilized using a clamp technique for $1 \mathrm{~h}$ at each level. In level I the glucose was elevated to $60 \mathrm{mg} / 100 \mathrm{ml}$ above the fasting value, and in level II the circulating glucose was increased to $100 \mathrm{mg} / 100 \mathrm{ml}$ above fasting. * "Significant change compared with control $(P<0.05$ and $P<0.001$, respectively).

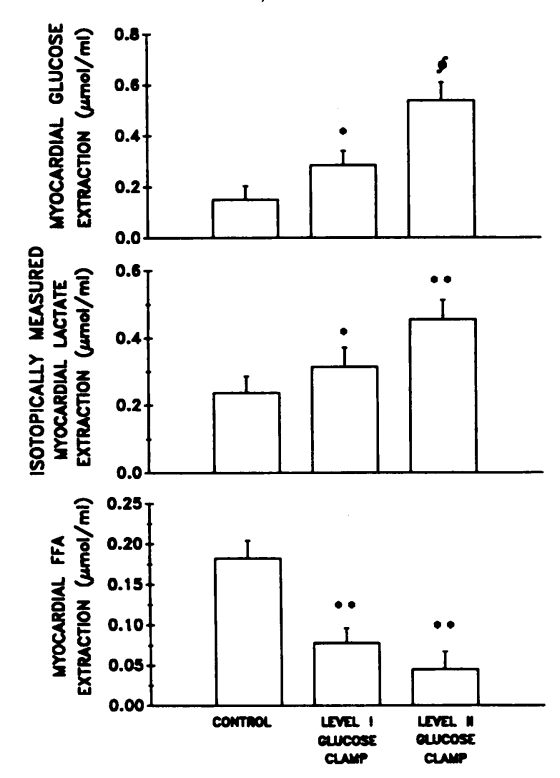

Figure 2. Histograms represent mean \pm 1 standard error of the myocardial glucose extraction (top), lactate extraction (middle) and free fatty acid (FFA) extraction (bottom) for fasting (control) and level I and level II hyperglycemic conditions. Myocardial glucose and free fatty acid extractions were determined by the arterial and coronary sinus differences. $\left[\mathrm{U}-{ }^{13} \mathrm{C}\right]$ Lactate was infused as a tracer, and the lactate extraction was obtained by isotopic analysis. *** §Significant change in myocardial extraction compared with control $(P$ $<0.05, P<0.01$, and $P$ $<0.005$, respectively). 
Determinants of glucose uptake. Simple linear regression analysis showed a positive correlation between the circulating glucose concentration and myocardial glucose uptake, $r$ $=0.57, P<0.001$ (Fig. 3). The relationship between arterial FFA and myocardial glucose uptake is shown in Fig. 4; a highly significant inverse correlation was observed, $r=-0.66$, $P<0.001$. Multiple linear regression analysis was performed to evaluate the influence of arterial FFA and arterial glucose as important variables on myocardial glucose uptake. The $t$ value was $0.716(P=0.488)$ for arterial glucose and $-2.560(P$ $=0.016$ ) for arterial FFA. This implies that the arterial FFA concentration is the more predictive variable in determining myocardial glucose uptake.

Net alanine flux. The mean arterial blood alanine concentration was $243 \pm 54 \mathrm{nmol} / \mathrm{ml}$ during control and both levels of the clamp. During the two levels of hyperglycemia, there were no significant changes in the arterial alanine concentration. In one subject A - CS blood alanine concentrations showed minimal myocardial extraction, and in the other six subjects there was evidence of alanine production during fasting conditions; the mean A - CS alanine difference was $-9 \pm 8 \mathrm{nmol} /$ $\mathrm{ml}$. There were no statistically significant changes in net myocardial alanine flux during the glucose clamp; $-14 \pm 10 \mathrm{nmol} /$ $\mathrm{ml}$ during level I $(P=0.19)$ and $-15 \pm 10 \mathrm{nmol} / \mathrm{ml}$ during level II $(P=0.11)$. In this study, simple linear regression analysis did not indicate any significant correlations between A - CS alanine and glucose extraction $(r=-0.06, P=\mathrm{NS})$ nor A $-\mathrm{CS}$ alanine and $\left[{ }^{13} \mathrm{C}\right]$ lactate extraction $(r=-0.12, P=\mathrm{NS})$.

Oxygen extraction ratios (OERs). The A - CS oxygen content difference was $11.97 \pm 0.40 \mathrm{ml} / 100 \mathrm{ml}$ during control, $10.95 \pm 0.85(P<0.05)$ and $11.13 \pm 0.51 \mathrm{ml} / 100 \mathrm{ml}(P<0.05)$, respectively, during level I and II of the glucose clamp. The OERs are expressed as a percentage of the A - CS oxygen difference in $\mu \mathrm{mol} / \mathrm{ml}$. The OER calculated for the A - CS glucose difference was $17 \pm 15 \%$ during control and increased to $35 \pm 15 \%$ during level I hyperglycemia and to $74 \pm 26 \%$ during level II. The lactate OER based on the $\left[{ }^{13} \mathrm{C}\right]$ extraction was $13 \pm 7 \%, 17 \pm 7 \%$ and $27 \pm 8 \%$, respectively. These values for FFA were $84 \pm 24 \%, 39 \pm 20 \%$ and $22 \pm 22 \%$, respectively. The OERs for these three exogenous substrates totaled $114 \%$ during fasting conditions and $123 \%$ during level II hyperglycemia.

Exogenous glucose oxidation. Glucose was specifically labeled with ${ }^{14} \mathrm{C}$ in the sixth position; this carbon is removed in the citric acid cycle (44). By measuring the myocardial production of ${ }^{14} \mathrm{CO}_{2}$, the amount of exogenous glucose undergoing immediate oxidation can be determined. Fig. 5 compares the

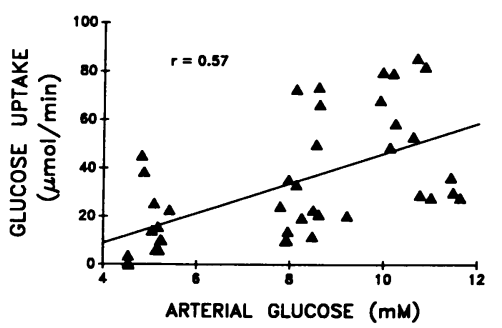

Figure 3. The myocardial glucose uptake expressed as $\mu \mathrm{mol} / \mathrm{min}$ is plotted against the arterial concentration of glucose. The glucose uptake was determined from the arterial and coronary sinus glucose difference in $\mu \mathrm{mol} / \mathrm{ml}$

$X$ the coronary sinus flow in $\mathrm{ml} / \mathrm{min}$. The data points were obtained during fasting and both levels of hyperglycemia. Simple linear regression analysis gives $r=0.57, P<0.001, y=6.23 x-15.96$; SE of the estimate $y$ on $x=1.42 \mu \mathrm{mol} / \mathrm{min}$.

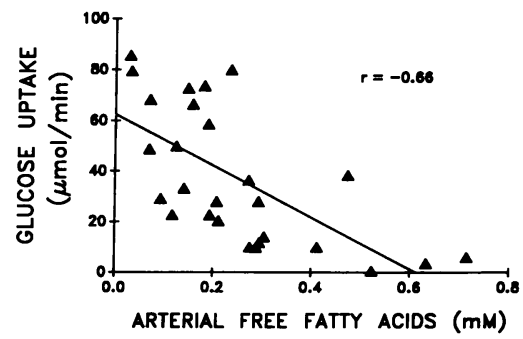

Figure 4. The correlation between the arterial free fatty acid concentration and myocardial glucose uptake expressed as $\mu \mathrm{mol} / \mathrm{min}$ is shown. The glucose uptake was determined from the arterial and coronary sinus glucose difference in $\mu \mathrm{mol} / \mathrm{ml}$

$X$ the coronary sinus flow in $\mathrm{ml} / \mathrm{min}$. The data points represent fasting and level I and level II of the glucose clamp. Simple linear regression analysis gives $r=-0.66, P<0.001, y=-102.10 x+62.54$; $\mathrm{SE}$ of the estimate $y$ on $x=23.28 \mu \mathrm{mol} / \mathrm{min}$.

myocardial glucose extraction with the amount of exogenous glucose being oxidized. As shown, during fasting conditions glucose oxidation was $0.02 \pm 0.03 \mu \mathrm{mol} / \mathrm{ml}$; this represents $9 \pm 10 \%$ of the extracted glucose. During level I of the glucose clamp, there was no significant increase in the amount of glucose oxidized $(0.04 \pm 0.05 \mu \mathrm{mol} / \mathrm{ml}, P=0.11$ compared with the above control value). During level II, there was a significant increase in exogenous glucose oxidation $(0.18 \pm 0.08$ $\mu \mathrm{mol} / \mathrm{ml}, P<0.01$ compared with control). However, despite this increase, only $32 \pm 10 \%$ of the glucose extracted was oxidized immediately.

The oxygen equivalent can be calculated for the amount of exogenous glucose oxidized based on the ${ }^{14} \mathrm{CO}_{2}$ data. In contrast to the OERs based on the A - CS glucose difference, the ${ }^{14} \mathrm{CO}_{2}$ data indicate that the contribution of exogenous glucose to myocardial oxidative metabolism was only $3 \pm 4 \%$ during fasting conditions, $6 \pm 6 \%$ during level $I$ and increased to $24 \pm 7 \%$ during level II of the glucose clamp $(P=0.005)$. Although there was a significant increase during hyperglycemia, these results imply that the immediate oxidation of exogenous glucose provides only a quarter of the energy required for myocardial oxidative metabolism even under optimal conditions for glucose metabolism.

Myocardial lactate release. $\mathrm{L}-\left[\mathrm{U}-{ }^{13} \mathrm{C}\right]$ Lactate was used as a tracer and an isotopic extraction for lactate was determined. In all subjects the isotopic extraction was greater than the chemical lactate difference during both fasting (control) and hyperglycemia. This finding indicates that the myocardium was releasing (producing) lactate $(33,34)$. During level II of the glu-

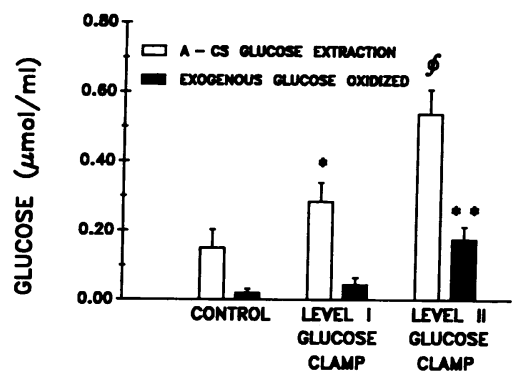

Figure 5. The arterial (A) and coronary sinus (CS) glucose difference (solid white bars) is compared with the exogenous glucose oxidation (solid black bars) during fasting (control) and level I and level II of the glucose clamp. Glucose oxidation was determined from the myocardial production of ${ }^{14} \mathrm{CO}_{2}$ and the specific activity of arterial glucose. The histograms represent the mean $\pm 1 \mathrm{SE} .{ }^{* * *} \$$ Significant change compared with control $(P<0.05, P<0.01$, and $P<0.005$, respectively). 


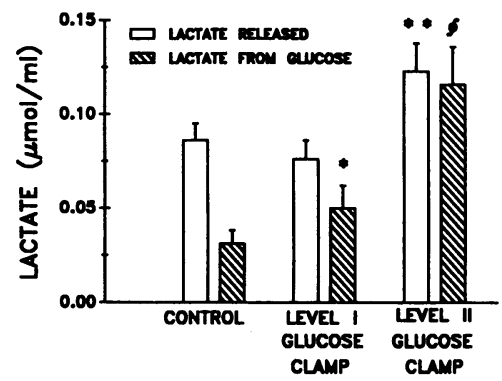

SE. The amount of lactate released was calculated from the difference in the isotopic and chemical lactate extraction. Measuring the specific activities $\left({ }^{14} \mathrm{C}\right)$ of glucose and lactate and the ${ }^{13} \mathrm{C}$ enrichment of lactate in the arterial and coronary sinus samples allowed quantitation of the myocardial conversion of exogenous glucose to lactate release. ${ }^{* * *}$ \& Significant change compared with control $(P<0.05, P$ $<0.01$ and $P<0.005$, respectively).

cose clamp, there was a slight increase in lactate release compared with control and level I; this small increase was statistically significant at $P<0.01$ (Fig. 6).

By infusing both $\left[6-{ }^{14} \mathrm{C}\right]$ glucose and $\left[\mathrm{U}-{ }^{13} \mathrm{C}\right]$ lactate and measuring the specific activities $\left({ }^{14} \mathrm{C}\right)$ of glucose and lactate and the enrichment of $\left[\mathrm{U}-{ }^{13} \mathrm{C}\right]$ lactate in the artery and coronary sinus, we are able to quantitate the contribution of exogenous glucose to lactate release. As shown in Fig. 6, $40 \pm 30 \%$ of the lactate release was derived from exogenous glucose during control. These values were significantly increased during both level I and level II hyperglycemia $(74 \pm 52 \%, P<0.05$, and $97 \pm 37 \%, P<0.005$, respectively).

Metabolic fate of glucose. Fig. 7 presents the percentage of extracted glucose undergoing immediate oxidation, being converted and released as lactate or being stored as glycogen. During control conditions $9 \pm 10 \%$ of the extracted glucose was oxidized and $13 \pm 9 \%$ was converted and released as lactate. The remainder of the glucose extracted $(78 \%)$ was assumed to be stored as glycogen.

During acute short-term hyperglycemia there was a significant increase in the contribution of exogenous glucose to lactate release (Fig. 6). However, the percentages of the extracted glucose going to lactate during levels I and II of the glucose clamp were not changed significantly from control ( $13 \pm 9 \%$ vs. $9 \pm 3 \%$ and $11 \pm 6 \%$, respectively, Fig. 7). The percentages of extracted glucose oxidized increased during hyperglycemia ( $13 \pm 11 \%$ during level I and $32 \pm 10 \%$ during level II). Despite the increase in glucose oxidation during level II, the majority of glucose extracted (57\%) continued to be stored as glycogen during this phase of hyperglycemia.

Control subjects. Two healthy male subjects ages 19 and 22 served as controls for the hyperglycemic protocol, i.e., D-[6$\left.{ }^{14} \mathrm{C}\right]$ glucose and $\mathrm{L}-\left[\mathrm{U}-{ }^{13} \mathrm{C}\right]$ lactate were infused at the same rate and for the same duration as the hyperglycemic protocol but the circulating glucose was not elevated in these subjects. The mean arterial glucose, lactate and FFA concentrations were $4.80,0.56$ and $0.89 \mu \mathrm{mol} / \mathrm{ml}$, respectively. The circulating substrate concentrations did not change significantly over the course of the study. The A - CS glucose difference was $\mathbf{0 . 1 6}$ $\mu \mathrm{mol} / \mathrm{ml}$. The $\left[{ }^{13} \mathrm{C}\right]$ lactate extraction was $0.09 \mu \mathrm{mol} / \mathrm{ml}$ and lactate release was $0.08 \mu \mathrm{mol} / \mathrm{ml}$ with $30 \%$ of this lactate being

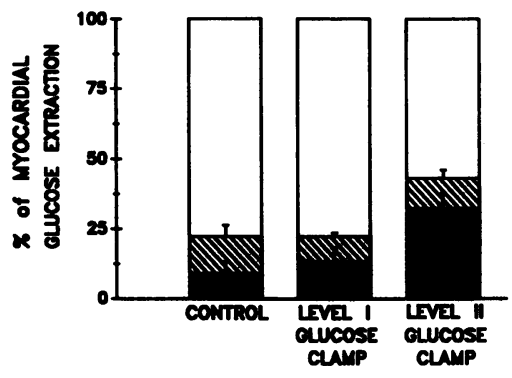

Figure 7. Myocardial glucose extraction is represented as $100 \%$ for fasting (control), level I and level II of the glucose clamp. The percentages of the extracted glucose undergoing immediate oxidation (solid black areas), being converted and released as lactate (hatched areas) and stored as glycogen (solid white areas) are shown.

derived from exogenous glucose. Only $3 \%$ of the exogenous glucose was oxidized. The $\mathrm{CS}-\mathrm{A}{ }^{14} \mathrm{CO}_{2}$ difference did not change during the duration of our sampling period, i.e., 45-180 min after the initiation of the isotope infusion. Thus, these data imply that the increase in glucose oxidation observed during hyperglycemia was secondary to the metabolic changes introduced by the glucose clamp and not due to the duration of the isotope infusion.

\section{Discussion}

This is the first study that investigates myocardial glucose oxidation and utilization during acute short-term hyperglycemia in normal humans. Circulating glucose was elevated to two levels (level I-150 mg/100 ml and level II-190 mg/100 ml), and the duration of each level was an hour. These glucose concentrations are similar to those after a carbohydrate meal; however the duration of hyperglycemia in this study was significantly longer than that observed postprandial in nondiabetics. In this study endogenous insulin was not suppressed and the arterial FFA were allowed to fall. Under these conditions, increases in myocardial glucose extraction were observed with each level of hyperglycemia. We also found that immediate oxidation of exogenous glucose was enhanced; however, during level II with circulating glucose levels of 190 $\mathrm{mg} / 100 \mathrm{ml}$ for an hour, the exogenous glucose oxidation only accounted for $25 \%$ of myocardial oxidative metabolism.

Previous studies have concluded that glucose contributes $15-55 \%$ of the energy needed for oxidative metabolism during fasting conditions and that this percentage increases to $65-100 \%$ during acute hyperglycemia (7-15). These conclusions were based on OER data which were calculated from the A - CS glucose difference with the assumption that the entire A - CS difference was oxidized immediately. OERs calculated on the A - CS glucose differences in the present study give similar results, i.e., $17 \%$ during fasting conditions and $74 \%$ during level II hyperglycemia. However, since glucose was labeled with ${ }^{14} \mathrm{C}$, the amount of exogenous glucose being oxidized immediately could be calculated from the myocardial production of ${ }^{14} \mathrm{CO}_{2}$. The ${ }^{14} \mathrm{CO}_{2}$ data imply that exogenous glucose supplied only $3 \%$ and $24 \%$ of the energy required for oxidative metabolism under fasting and level II hyperglycemia, respectively. Previous published experiments from our laboratory have shown that the extraction ratios obtained from $\left[1-{ }^{14} \mathrm{C}\right]$ lactate and $\left[\mathrm{U}-{ }^{13} \mathrm{C}\right]$ lactate are identical (45). Experi- 
ments using $\left[1-{ }^{14} \mathrm{C}\right]$ lactate and measuring ${ }^{14} \mathrm{CO}_{2}$ demonstrated that the A - CS lactate difference underestimates the myocardial lactate utilization by 20 to $40 \%$ and that $90-100 \%$ of the isotopic lactate extraction is oxidized immediately (46). Although we did not measure ${ }^{13} \mathrm{CO}_{2}$ in these subjects, we believe that $\left[\mathrm{U}-{ }^{13} \mathrm{C}\right]$ lactate extraction is a very close and reliable assessment of myocardial lactate oxidation. The OERs for $\left[{ }^{13} \mathrm{C}\right]-$ lactate were $13 \%$ and $27 \%$ during fasting and level II hyperglycemia, respectively. The sum contributions of exogenous glucose and lactate to oxidative metabolism were $16 \%$ and $51 \%$, respectively. Under fasting conditions, the OER for FFA was $84 \%$ and fell to $22 \%$ during level II. The total OERs based on the isotopic analyses for glucose and lactate and the A - CS FFA difference are $100 \%$ during control and $73 \%$ during level II hyperglycemia. The latter value raises the question of what substrate is providing the remaining $25-30 \%$ of the energy. The myocardium contains stores of glycogen and triglycerides. During level II of the glucose clamp almost $100 \%$ of the lactate release is derived from exogenous glucose (Fig. 6), therefore we believe that very little glycogen is being broken down and utilized under these conditions and that the triglyceride pools are probably the source of the remainder of the energy required for oxidative metabolism.

Infusing $\left[6-{ }^{14} \mathrm{C}\right]$ glucose and $\left[\mathrm{U}-{ }^{13} \mathrm{C}\right]$ lactate simultaneously enables us to quantitate myocardial lactate release and the contribution of exogenous glucose to the lactate released as well as glucose oxidation. Isotopic analysis showed that lactate was being released from the myocardium despite net $(A-C S)$ chemical lactate extraction in these healthy normal subjects. During level II of the hyperglycemic clamp, we observed a slight but statistically significant increase in myocardial lactate release compared with fasting values $(0.09 \pm 0.02 \mu \mathrm{mol} / \mathrm{ml}$ vs. $0.12 \pm 0.03 \mu \mathrm{mol} / \mathrm{ml}, P<0.01)$. The glucose oxidation and $\left[{ }^{13} \mathrm{C}\right]$ lactate data previously discussed suggest that pyruvate dehydrogenase activity is markedly increased during the hyperglycemic conditions of our study. Thus, we believe that this slight increase in lactate release is related to enhanced activity in the glycolytic pathway.

During fasting conditions, we also found that $<50 \%$ of the lactate released was derived from exogenous glucose. However during both levels of hyperglycemia in this study, the contribution of exogenous glucose to lactate release significantly increased over fasting values (Fig. 6). This finding indicates that elevating glucose under the conditions of this study results in an increase in the relative contribution of exogenous glucose to the total glycolytic carbon flux compared with fasting conditions.

After myocardial extraction, glucose is immediately phosphorylated. Glucose 6 - phosphate can enter several different metabolic pathways within the myocardial cell: conversion to pyruvate via glycolysis, conversion to ribose via the pentose pathway or conversion to glycogen $(47,48)$. Pyruvate can undergo oxidative decarboxylation to acetyl-coenzyme A, which enters the citric acid cycle. The carbon in the sixth position on glucose is released in the citric acid cycle (44); thus, measuring myocardial ${ }^{14} \mathrm{CO}_{2}$ production allows us to quantitate the amount of exogenous glucose undergoing immediate oxidation. Pyruvate can also be converted to lactate and released from the cell. As described above, L-[U- $\left.{ }^{13} \mathrm{C}\right]$ lactate was used as a tracer in order to measure myocardial lactate release. The ${ }^{13} \mathrm{C}$ enrichment of lactate and the specific activities $\left({ }^{14} \mathrm{C}\right)$ of glucose and lactate were determined to quantitate the contribution of exogenous glucose to lactate release. Pyruvate can also be converted to alanine via a transaminase reaction $(48,49)$. Alanine concentrations were measured in this study. In these young healthy subjects, we found that the myocardium was producing a small amount of alanine. The specific activity $\left({ }^{14} \mathrm{C}\right)$ of alanine was not measured. However, if all the alanine produced was derived from exogenous glucose, this could only account for $3 \%$ of the extracted glucose during fasting and $2 \%$ during hyperglycemic conditions in this study.

Glucose 6-phosphate can also be converted to ribose via the pentose pathway (50). Since the carbon in the first position on glucose is released as $\mathrm{CO}_{2}$ in this pathway (44), the amount of glucose being shunted through this metabolic pathway would not be detected in our experiments using $\mathrm{D}-\left[6-{ }^{14} \mathrm{C}\right]-$ glucose. However, animal experiments have shown that in the adult, noninfarcted myocardium the metabolic activity in the pentose pathway is very low $(44,48,51)$.

Glucose may also be stored in the myocardium as glycogen. The enzymes involved in the regulation of the rate of glycogen synthesis and breakdown are controlled by various hormones and intracellular metabolic intermediates (52-55). In the fasting state with high circulating FFA concentrations, myocardial glycogen stores increase (55). Animal studies have also shown that with exercise or ischemia the myocardial glycogen content falls significantly (56-59). Under basal conditions, myocardial glycogen has a slow turnover of 5-6 h (60, 61). The stability of the $\mathrm{CS}-\mathrm{A}{ }^{14} \mathrm{CO}_{2}$ difference over the $3 \mathrm{~h}$ of isotope infusion in the two control subjects also implies a slow glycogen turnover during fasting conditions. We have evidence that the ${ }^{14} \mathrm{C}$ label has equilibrated with the $\mathrm{CO}_{2}$ pool (33); however, since glycogen has such a slow turnover, we do not believe that the ${ }^{14} \mathrm{C}$ label has achieved a steady state with the glycogen pool. Therefore the amount of ${ }^{14} \mathrm{C}$ label that remains unrecovered is assumed to be incorporated into myocardial glycogen. During hyperglycemia, endogenous insulin increases. Studies in skeletal muscle and myocardium have shown that insulin increases the activity of glycogen synthase, the rate-limiting enzyme for muscle glycogen synthesis (62-64). Because of the activation of the enzyme glycogen synthase, the myocardial glycogen pool size probably increased under the conditions of our experiment. The amount of ${ }^{14} \mathrm{C}$ label that remained unrecovered during level I and level II of the glucose clamp would argue in favor of an expansion of the glycogen stores. A limitation of this investigation in humans is that the myocardial glycogen content could not be measured. However using the isotopic data, we can make the following calculations. The difference between the total lactate release and the lactate coming from exogenous glucose presumably represents the contribution of glycogen to nonoxidative glycolysis. This same relative ratio of exogenous glucose to endogenous glucose (glycogen) is probably entering glycolysis and being oxidized. Based on these assumptions and that the myocardial blood flow is $1 \mathrm{ml} / \mathrm{min}$ per $\mathrm{g}$, estimations of glycogen synthesis and breakdown can be made. During fasting control conditions, we calculated that in $1 \mathrm{~h} 7.0 \mu \mathrm{mol} / \mathrm{g}$ of glycogen (expressed as glucosyl units) was synthesized from the exogenous glucose extracted and that $1.7 \mu \mathrm{mol} / \mathrm{g}$ of glycogen was broken down and appears as unlabeled lactate release and an additional $2.2 \mu \mathrm{mol} / \mathrm{g}$ was oxidized. Therefore, in $1 \mathrm{~h}$ under these control conditions, there was a net increase of $3.1 \mu \mathrm{mol} / \mathrm{g}$ 
of glycogen. Similar calculations suggest that during the $1 \mathrm{~h}$ of level I hyperglycemia, there was a net increase of $11.1 \mu \mathrm{mol} / \mathrm{g}$ and for level II a net increase of $18.4 \mu \mathrm{mol} / \mathrm{g}$. Thus, these estimations imply that over the course of this study $(3 \mathrm{~h})$, the glycogen content increased by $\sim 33 \mu \mathrm{mol} / \mathrm{g}$ of myocardium. Biopsies performed during cardiac surgery in humans and animal studies have shown that the myocardial glycogen stores are increased after glucose infusions $(23,25,26,65)$. Lolley and his colleagues used a high fat diet and a glucose-insulinpotassium infusion to elevate myocardial glycogen in patients prior to cardiac surgery and reported a $47-\mu \mathrm{mol} / \mathrm{g}$ ( 93 vs. 46 $\mu \mathrm{mol} / \mathrm{g}$ ) difference in the glycogen contents from biopsies obtained immediately before cardiac bypass (24). Thus, the estimated increase in glycogen stores in this study is well within the range observed by other investigators. In the normal physiologic state, hyperglycemia of $190 \mathrm{mg} / 100 \mathrm{ml}$ is transient and not sustained for hours. However in the diabetic state with prolonged hyperglycemia and elevated circulating FFA, the myocardial glycogen content can be markedly increased compared with nondiabetics (66).

In the fasting state circulating FFA are a major determinant of myocardial glucose utilization $(7,48,67,68)$. Previous studies in fasting humans have reported highly significant inverse correlations between arterial FFA concentrations and myocardial glucose extraction $(11,33)$. We have previously shown that FFA concentrations are also inversely correlated with the percentage of extracted glucose undergoing oxidation in fasting human subjects (33). Randle et al. have shown in isolated heart experiments that glucose uptake and oxidation are both inhibited by high circulating concentrations of FFA at several enzymatic steps in the glycolytic pathway (69). The supply of ATP in the cell regulates the various pathways. If the cell is utilizing FFA, the ATP level is high and the level of acetyl-coenzyme A increased. With high levels of acetyl-coenzyme A, the enzyme pyruvate dehydrogenase is inhibited. This enzyme is involved in the oxidative decarboxylation of pyruvate; thus, inhibition of this enzyme blocks entry of glucose into the citric acid cycle. Also, when the myocardium is actively utilizing FFA, there is a build-up of citrate. Citrate inhibits the enzyme phosphofructokinase in the glycolytic pathway. When this latter enzyme is blocked, glucose 6-phosphate accumulates in the cell. As this occurs, hexokinase is inhibited and the rate of glucose phosphorylation declines. In the present investigation there was a fall in FFA concentration which would remove these inhibitory effects and result in an increase in glucose uptake and the glycolytic rate.

In the present study the circulating glucose concentration was elevated and stabilized; and endogenous insulin was not suppressed and therefore increased during the glucose infusion. In addition to enhancing glucose uptake and metabolism, insulin also inhibits lipolysis in vivo (70). Thus the circulating concentrations of FFA fell significantly during our study (Fig. 1). Multiple linear regression analysis was performed to determine the relationship between arterial glucose and arterial FFA with myocardial glucose uptake. This analysis showed that in our study the arterial FFA were significantly inversely correlated with glucose uptake, and that the addition of arterial glucose did not increase the level of significance. Barrett et al. (71) also reported that the arterial FFA suppression was more important than hyperglycemia in the regulation of myocardial glucose uptake. In conscious dogs, Barrett and his colleagues compared myocardial glucose uptake during a euglycemic insulin clamp with and without Intralipid infusion to raise FFA, with glucose uptake during a hyperglycemic clamp using somatostatin administration to inhibit endogenous insulin. These investigators found that glucose uptake was markedly enhanced during the insulin clamp when lipolysis was suppressed and the FFA concentrations were lower. Hyperglycemia, by itself, had little influence on glucose uptake. Myocardial glucose oxidation was not assessed in their study.

The major metabolic pathways linking carbohydrate and amino acid metabolism include the conversion of pyruvate to alanine and $\alpha$-ketoglutarate to glutamic acid (49). Previous studies have shown that there is significant net production of alanine and net uptake of glutamate by the myocardium (72-74). The amounts of alanine produced and glutamate extracted were significantly higher in subjects with ischemic heart disease compared with those without coronary artery disease (72-74). Thomassen et al. reported that myocardial alanine production and glutamate extraction were also positively correlated with glucose and lactate extraction (74). In the present study the mean A - CS alanine difference was $-9 \pm 8$ $\mathrm{nmol} / \mathrm{ml}$ during control. During level I and level II of the glucose clamp, there was a slight but not statistically significant increase in alanine production. No correlation was found between myocardial alanine flux with glucose or lactate extraction in our study. Glutamate concentrations were not measured. Our findings may differ from those of Thomassen et al. (74) because of subject selection. In the present study only healthy young normal male subjects (mean age $24 \pm 4$ yr) were included while Thomassen and his colleagues included subjects (mean age $54 \pm 10 \mathrm{yr}$ ) with chest pain whose diagnostic coronary arteriograms demonstrated no significant lesions. Thus, the relationship between this transaminase reaction and glycolysis may be related to cardiac disease or aging.

In summary, this study demonstrates that despite a marked increase in myocardial glucose extraction during acute hyperglycemia, exogenous glucose oxidation only accounts for less than one-third of myocardial oxidative metabolism. During short-term periods of elevated circulating glucose (i.e. $2 \mathrm{~h}$ ), there is evidence of increase in the contribution of exogenous glucose to the glycolytic carbon flux; however, the majority of exogenous glucose is probably stored as glycogen.

\section{Acknowledgments}

We express our appreciation to Maria Mayr, Eileen McCauley, and Robert Jaskot for their assistance with the biochemical assays, and to Barbara Miller for her technical assistance in the cardiac catheterization laboratory.

This work was supported in part by the Medical Research Service of the Veterans Administration, San Francisco, California and by grant HL-25625 from the National Institutes of Health, Bethesda, MD. W. C. Stanley was the recipient of a Postdoctoral Fellowship from the California Affiliate of the American Heart Association, with funding provided by the Orange County and San Francisco Chapters.

\section{References}

1. DeFronzo, R. A., J. D. Tobin, and R. Andres. 1979. Glucose clamp technique: A method for quantifying insulin secretion and resistance. Am. J. Physiol. 237:E214-E223. 
2. Ferrannini, E., J. D. Smith, C. Cobelli, G. Toffolo, A. Pilo, and R. A. DeFronzo. 1985. Effect of insulin on the distribution and disposition of glucose in man. J. Clin. Invest. 76:357-364.

3. Golay, A., R. A. DeFronzo, E. Ferrannini, D. C. Simonson, D. Thorin, K. Acheson, D. Thiebaud, B. Curchod, E. Jequier, and J. P. Felber. 1988. Oxidative and non-oxidative glucose metabolism in non-obese type 2 (non-insulin-dependent) diabetic patients. Diabetologia. 31:585-591.

4. DeFronzo, R. A., R. Gunnarsson, O. Bjorkman, M. Olsson, and J. Wahren. 1985. Effects of insulin on peripheral and splanchnic glucose metabolism in noninsulin-dependent (type II) diabetes mellitus. J. Clin. Invest. 76:149-155.

5. Mikines, K. J., P. A. Farrell, B. Sonne, B. Tronier, and H. Galbo. 1988. Postexercise dose-response relationship between plasma glucose and insulin secretion. J. Appl. Physiol. 64:988-999.

6. Richter, E. A., K. J. Mikines, H. Galbo, and B. Kiens. 1989. Effect of exercise on insulin action in human skeletal muscle. J. Appl. Physiol. 66:876-885.

7. Opie, L. H. 1969. Metabolism of the heart in health and disease. Part II. Am. Heart J. 77:100-122.

8. Rogers, W. J., R. O. Russell, Jr., H. G. McDaniel, and C. E. Rackley. 1977. Acute effects of glucose-insulin-potassium infusion on myocardial substrates, coronary blood flow and oxygen consumption in man. Am. J. Cardiol. 40:421-428.

9. Kaijser, L. 1980. Effect of metabolic intervention on substrate metabolism in the human heart. In Advances in Myocardiology. Vol. 2. M. Tajuddin, B. Bhatia, H. H. Siddiqui, and G. Rona, editors. University Park Press, Baltimore. 51-59.

10. Kaijser, L., B. W. Lassers, M. L. Wahlqvist, and L. A. Carlson. 1972. Myocardial lipid and carbohydrate metabolism in fasting men during prolonged exercise. J. Appl. Physiol. 32:847-858.

11. Lassers, B. W., L. Kaijser, and L. A. Carlson. 1972. Myocardial lipid and carbohydrate metabolism in healthy, fasting men at rest: studies during continuous infusion of $3 \mathrm{H}$-palmitate. Eur. J. Clin. Invest. 2:348-358.

12. Goodale, W. T., and D. B. Hackel. 1953. Myocardial carbohydrate metabolism in normal dogs, with effects of hyperglycemia and starvation. Circ. Res. 1:509-517.

13. Goodale, W. T., R. E. Olson, and D. B. Hackel. 1959. The effects of fasting and diabetes mellitus on myocardial metabolism in man. Am. J. Med. 27:212-220.

14. Bing, R. J. 1955. The metabolism of the heart. Harvey Lect. $50: 27-70$

15. Bing, R. J., A. Siegel, A. Vitale, F. Balboni, E. Sparks, M. Taeschler, M. Klapper, and S. Edwards. 1953. Metabolic studies on the human heart in vivo. I. Studies on carbohydrate metabolism of the human heart. Am. J. Med. 15:284-296.

16. Goulston, A. 1911. The beneficial effect of ingestion of cane sugar in certain forms of heart disease. Br. Med. J. i:615.

17. Budingen, T. 1914. Uber die Moglichkeit einer Ernahrungsbehandlung des Herzmuskels durch Einbringen von Traubenzuckerlosungen in den groben Kreislauf. Dt. Arch. Klin. Med. 114:534-579.

18. Sodi-Pallares, D., A. Bisteni, G. A. Medrano, M. R. Testelli, and A. DeMicheli. 1963. The polarizing treatment of acute myocardial infarction. Dis. Chest. 43:424-432.

19. Sodi-Pallares, D., M. R. Testelli, B. L. Fishleder, A. Bisteni, G. A. Medrano, C. Friedland, and A. DeMicheli. 1962. Effects of an intravenous infusion of a potassium-glucose-insulin solution on the electrocardiographic signs of myocardial infarction. Am. J. Cardiol. 9:166-181.

20. Rogers, W. J., A. W. Stanley, Jr., J. B. Breinig, J. W. Prather, H. G. McDaniel, R. E. Moraski, J. A. Mantle, R. O. Russell, Jr., and C. E. Rackley. 1976. Reduction of hospital mortality rate of acute myocardial infarction with glucose-insulin-potassium infusion. $\mathrm{Am}$. Heart J. 92:441-454.

21. Rackley, C. E., R. O. Russell, Jr., W. J. Rogers, J. A. Mantle, H. G. McDaniel, and S. E. Papapietro. 1981. Clinical experience with glucose-insulin-potassium therapy in acute myocardial infarction. $\mathrm{Am}$. Heart J. 102:1038-1049.

22. Whitlow, P. L., W. J. Rogers, L. R. Smith, H. G. McDaniel, S. E. Papapietro, J. A. Mantle, J. R. Logic, R. O. Russell, Jr., and C. E. Rackley. 1982. Enhancement of left ventricular function by glucoseinsulin-potassium infusion in acute myocardial infarction. Am. J. Cardiol. 49:811-820.

23. Oldfield; G. S., P. J. Commerford, and L. H. Opie. 1986. Effects of preoperative glucose-insulin-potassium on myocardial glycogen levels and on complications of mitral valve replacement. J. Thorac. Cardiovasc. Surg. 91:874-878.

24. Lolley, D. M., W. O. Myers, and D. A. Tewksbury. 1979. Importance of preoperative myocardial glycogen levels in human cardiac preservation. J. Thorac. Cardiovasc. Surg. 78:678-687.

25. Berggren, H., R. Ekroth, J. Herlitz, A. Hjalmarson, A. Waldenstrom, J. Waldenstrom, and G. William-Olsson. 1982. Improved myocardial protection during cold cardioplegia by means of increased myocardial glycogen stores. Thorac. Cardiovasc. Surgeon. 30:389392.

26. Iyengar, S. R. K., E. J. P. Charrette, C. K. S. Iyengar, and S. Wasan. 1976. Myocardial glycogen in prevention of perioperative ischemic injury of the heart: A preliminary report. Can. J. Surg. 19:246251.

27. Haider, W., H. Benzer, W. Schutz, and E. Wolner. 1984. Improvement of cardiac preservation by preoperative high insulin supply. J. Thorac. Cardiovasc. Surg. 88:294-300.

28. Opie, L. H., and P. Owen. 1976. Effect of glucose-insulin-potassium infusions on arteriovenous differences of glucose and of free fatty acids and on tissue metabolic changes in dogs with developing myocardial infarction. Am. J. Cardiol. 38:310-321.

29. Opie, L. H., K. Bruyneel, and P. Owen. 1975. Effects of glucose, insulin, and potassium infusion on tissue metabolic changes within first hour of myocardial infarction in the baboon. Circulation. 52:4957.

30. Maroko, P. R., P. Libby, B. E. Sobel, C. M. Bloor, H. D. Sybers, W. E. Shell, J. W. Covell, and E. Braunwald. 1972. Effect of glucoseinsulin-potassium infusion on myocardial infarction following experimental coronary artery occlusion. Circulation. 45:1160-1175.

31. Chiong, M. A., R. West, and J. O. Parker. 1976. The protective effect of glucose-insulin-potassium on the response to atrial pacing. Circulation. 54:37-46.

32. Bruce, R. A., and T. R. Hornsten. 1969. Exercise stress testing in evaluation of patients with ischemic disease. Prog. Cardiovasc. Dis. 11:371-390.

33. Wisneski, J. A., E. W. Gertz, R. A. Neese, L. D. Gruenke, D. L. Morris, and J. C. Craig. 1985. Metabolic fate of extracted glucose in the normal human myocardium. J. Clin. Invest. 76:1819-1827.

34. Gertz, E. W., J. A. Wisneski, R. A. Neese, J. D. Bristow, G. L. Searle, and J. T. Hanlon. 1981. Myocardial lactate metabolism: evidence of lactate release during net chemical extraction in man. Circulation. 63:1273-1279.

35. Ganz, W., K. Tamura, H. S. Marcus, R. Donoso, S. Yoshida, and H. J. C. Swan. 1971. Measurement of coronary sinus blood flow by continuous thermodilution in man. Circulation. 44:181-195.

36. Tserng, K. Y., C. A. Gilfillan, and S. C. Kalhan. 1984. Determination of carbon-13 labeled lactate in blood by gas chromatography/ mass spectrometry. Anal. Chem. 56:517-523.

37. Gruenke, L. D., J. C. Craig, and D. M. Bier. 1980. An improved selected ion recording system for precise isotope ratio determination. Biomed. Mass Spectrom. 7:381-384.

38. Hagenfeldt, L. 1967. A simplified procedure for the measurement of ${ }^{14} \mathrm{CO}_{2}$ in blood. Clin. Chim. Acta. 18:320-321.

39. Ko, H., and M. E. Royer. 1974. A gas-liquid chromatographic assay for plasma free fatty acids. J. Chromatogr. 88:253-263.

40. Yalow, R. S., and S. A. Berson. 1960. Immunoassay of endogenous plasma insulin in man. J. Clin. Invest. 39:1157-1175.

41. Williamson, D. H. 1963. L-Alanine: Determination with ala- 
nine dehydrogenase. In Methods of Enzymatic Analysis. H. U. Bergmeyer, editor. Academic Press, New York. 1679-1685.

42. Van Slyke, D. D., and J. M. Neill. 1924. Determination of gases in blood and other solutions by vacuum extraction and manometric measurement. J. Biol. Chem. 61:523-573.

43. Zar, J. H. 1974. Biostatistical Analysis. Prentice-Hall, Inc, Englewood Cliffs, NJ. 198-280.

44. Lehninger, A. L. 1975. Biochemistry. Worth Publishers, New York. 417-473.

45. Neese, R. A., E. W. Gertz, J. A. Wisneski, L. D. Gruenke, and J. C. Craig. 1983. A stable isotope technique for investigating lactate metabolism in humans. Biomed. Mass Spectrom. 10:458-462.

46. Gertz, E. W., J. A. Wisneski, W. C. Stanley, and R. A. Neese. 1988. Myocardial substrate utilization during exercise in humans: dual carbon-labeled carbohydrate isotope experiments. J. Clin. Invest. 82:2017-2025.

47. Taegtmeyer, H. 1985. Carbohydrate interconversions and energy production. Circulation. 72(Suppl. IV):1-8.

48. Randle, P. J., and P. K. Tubbs. 1979. Carbohydrate and fatty acid metabolism. In Handbook of Physiology, The Cardiovascular System Vol. I. The Heart. R. M. Berne, editor. Waverly Press, Inc., Baltimore, MD. 805-844.

49. Kaplan, J. H., and H. C. Pitot. 1970. The regulation of intermediary amino acid metabolism in animal tissues. In Mammalian Protein Metabolism. Vol. IV. H. N. Munro, editor. Academic Press, Inc., New York. 387-443.

50. Randle, P. J., E. A. Newsholme, and P. B. Garland. 1964. Regulation of glucose uptake by muscle. 8. Biochem. J. 93:652-665.

51. Opie, L. H. 1968. Metabolism of the heart in health and disease. Part 1. Am. Heart J. 76:685-698.

52. Mayer, S. E., B. J. Williams, and J. M. Smith. 1967. Adrenergic mechanisms in cardiac glycogen metabolism. Ann. NY Acad. Sci. 139:686-702.

53. Cornblath, M., P. J. Randle, A. Parmeggiani, and H. E. Morgan. 1963. Regulation of glycogenolysis in muscle. Effects of glucagon and anoxia on lactate production, glycogen content, and phosphorylase activity in the perfused isolated rat heart. J. Biol. Chem. 238:1592-1597.

54. Morgan, H. E., and A. Parmeggiani. 1964. Regulation of glycogenolysis in muscle. II. Control of glycogen phosphorylase reaction in isolated perfused heart. J. Biol. Chem. 239:2435-2439.

55. Adrouny, G. A., and J. A. Russell. 1956. Effects of growth hormone and nutritional status on cardiac glycogen in the rat. Endocrinology. 59:241-251.

56. Judd, W. T., and J. L. Poland. 1972. Myocardial glycogen changes with exercise. Proc. Soc. Exp. Biol. Med. 140:955-957.

57. Goldfarb, A. H., J. F. Bruno, and P. J. Buckenmeyer. 1986. Intensity and duration effects of exercise on heart cAMP, phosphorylase, and glycogen. J. Appl. Physiol. 60:1268-1273.

58. Marshall, R. C., W. W. Nash, K. I. Shine, M. E. Phelps, and N. Ricchiuti. 1981. Glucose metabolism during ischemia due to excessive oxygen demand or altered coronary flow in the isolated arterially perfused rabbit septum. Circ. Res. 49:640-648.
59. Taegtmeyer, H., A. F. C. Roberts, and A. E. G. Raine. 1985. Energy metabolism in reperfused heart muscle: metabolic correlates to return of function. J. Am. Coll. Cardiol. 6:864-870.

60. Van der Vusse, G. J., and R. S. Reneman. 1983. Glycogen and lipids (endogenous substrates). In Cardiac Metabolism. A. J. DrakeHolland and M. I. M. Noble, editors. John Wiley and Sons, Ltd., New York. 215-237.

61. Laughlin, M. R., W. A. Petit, Jr., J. M. Dizon, R. G. Shulman, and E. J. Barrett. 1988. NMR measurements of in vivo myocardial glycogen metabolism. J. Biol. Chem. 263:2285-2291.

62. Bogardus, C., S. Lillioja, K. Stone, and D. Mott. 1984. Correlation between muscle glycogen synthase activity and in vivo insulin action in man. J. Clin. Invest. 73:1185-1190.

63. Nuttall, F. Q., M. C. Gannon, V. A. Corbett, and M. P. Wheeler. 1976. Insulin stimulation of heart glycogen synthase D phosphatase (protein phosphatase). J. Biol. Chem. 251:6724-6729.

64. Miller, T. B., Jr. 1978. A dual role for insulin in the regulation of cardiac glycogen synthase. J. Biol. Chem. 253:5389-5394.

65. McElroy, D. D., H. Taegtmeyer, and W. E. Walker. 1987. Effects of glycogen on function and energy metabolism of the isolated rabbit heart after hypothermic ischemic arrest. Clin. Res. 35:304a.(Abstr.)

66. Chen, V., C. D. Ianuzzo, B. C. Fong, and J. J. Spitzer. 1984. The effects of acute and chronic diabetes on myocardial metabolism in rats. Diabetes. 33:1078-1084.

67. Neely, J. R., M. J. Rovetto, and J. F. Oram. 1972. Myocardial utilization of carbohydrate and lipids. Prog. Cardiovasc. Dis. 15:289329.

68. Liedtke, A. J. 1981. Alterations of carbohydrate and lipid metabolism in the acutely ischemic heart. Prog. Cardiovasc. Dis. 23:321336.

69. Randle, P. J., P. B. Garland, C. N. Hales, and E. A. Newsholme. 1963. The glucose fatty acid cycle: its role in insulin sensitivity and the metabolic disturbances of diabetes mellitus. Lancet. i:785-789.

70. Fain, J. N., V. P. Kovacev, and R. O. Scow. 1966. Antilipolytic effect of insulin in isolated fat cells of the rat. Endocrinology. 78:773778.

71. Barrett, E. J., R. G. Schwartz, C. K. Francis, and B. L. Zaret. 1984. Regulation by insulin of myocardial glucose and fatty acid metabolism in the conscious dog. J. Clin. Invest. 74:1073-1079.

72. Mudge, G. H., Jr., R. M. Mills, Jr., H. Taegtmeyer, R. Gorlin, and M. Lesch. 1976. Alterations of myocardial amino acid metabolism in chronic ischemic heart disease. J. Clin. Invest. 58:1185-1192.

73. Thomassen, A. R., T. T. Nielsen, J. P. Bagger, and P. Henningsen. 1983. Myocardial exchanges of glutamate, alanine and citrate in controls and patients with coronary artery disease. Clin. Sci. 64:3340 .

74. Thomassen, A., T. T. Nielsen, J. P. Bagger, and L. Thuesen. 1984. Myocardial glutamate and alanine exchanges related to carbohydrate metabolism in patients with normal and stenotic coronary arteries. Clin. Physiol. 4:425-434. 